\title{
Kissing Nevus of the Penis
}

\author{
Sook Jung Yun, M.D., Hyun Seung Wi, M.D., Jee-Bum Lee, M.D., Seong-Jin Kim, M.D., \\ Young Ho Won, M.D., Seung-Chul Lee, M.D.
}

Department of Dermatology, Chonnam National University Medical School, Gwangju, Korea

Kissing or divided nevi are similar in shape to congenital melanocytic nevi located on an adjacent part of the body that are separated during embryogenesis. Kissing nevi of the upper and lower eyelids have been reported infrequently since the first report in 1908. Kissing nevi of the penis are very rare, with only 12 cases being reported until now, and this is the first case report in the Korean dermatological literature. A previously healthy 27-year-old man presented with asymptomatic black colored patches, which were detected 10 years ago, on the glans penis and the prepuce with growth in size. We report here a case of kissing nevus of the penis, which showed an obvious mirror-image symmetry relative to the coronal sulcus. (Ann Dermatol 23(4) 512 514, 2011)

\section{-Keywords-}

Nevus, Pigmented

\section{INTRODUCTION}

Kissing nevi are a rare clinical variation of congenital melanocytic nevi that are located on adjacent sites of the body at which division occurs during embryogenesis. Since the first case report by Von Micheal in 1908, a few kissing nevi have been reported located on the upper and the lower eyelids ${ }^{1-3}$. A kissing nevus appears to be a single lesion when the lids are closed. These lesions are very

Received August 12, 2010, Revised December 8, 2010, Accepted for publication December 8, 2010

Corresponding author: Seung-Chul Lee, M.D., Department of Dermatology, Chonnam National University Medical School, 671 Jebong-ro, Dong-gu, Gwangju 501-757, Korea. Tel: 82-62-220-6682, Fax: 82-62-222-4058, E-mail: schul@chonnam.ac.kr

This is an Open Access article distributed under the terms of the Creative Commons Attribution Non-Commercial License (http:// creativecommons.org/licenses/by-nc/3.0) which permits unrestricted non-commercial use, distribution, and reproduction in any medium, provided the original work is properly cited. rare on the penis, with only 12 cases being reported to date in the English literature, and only one case reported a kissing nevus of the eyelids in the Korean dermatological literature $^{4-12}$. We report the first case of a patient with a kissing nevus located on the penis in the Korean dermatological literature.

\section{CASE REPORT}

In January 2010, a 27-year-old man presented with asymptomatic black colored patches on his penis that were detected 10 years ago when a circumcision was performed. On physical examination, $2.0 \times 1.5 \mathrm{~cm}$ and $1.5 \times 1.3 \mathrm{~cm}$-sized black colored patches were located on the prepuce and the lateral glans penis, respectively (Fig. 1). These lesions did not affect the coronal sulcus but were seen on each side of it. The lesions overlapped each other when the prepuce was retracted. His past and family histories were non contributory. Laboratory tests were within normal limits. A skin biopsy was performed on both patches. Histopathological findings showed nests of nevus cells in the dermal-epidermal junction and in the upper dermis (Fig. 2). Immunohistochemical stains revealed a partial positive for HMB45 and a strong positive

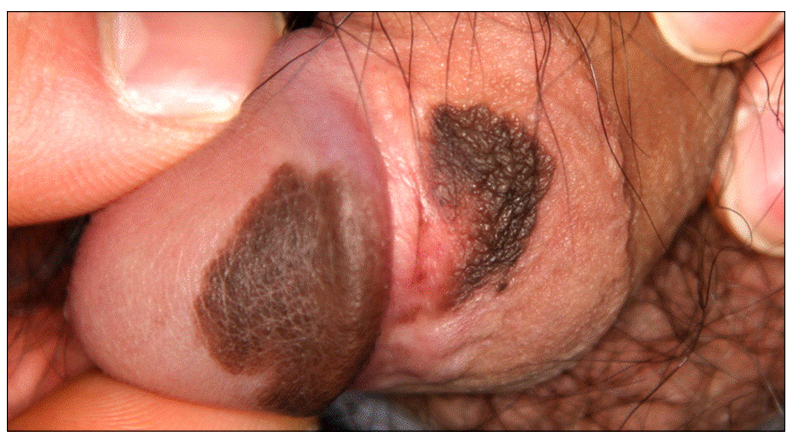

Fig. 1. Kissing nevi of the penis. Black colored patches on the glans and the prepuce laterally. 

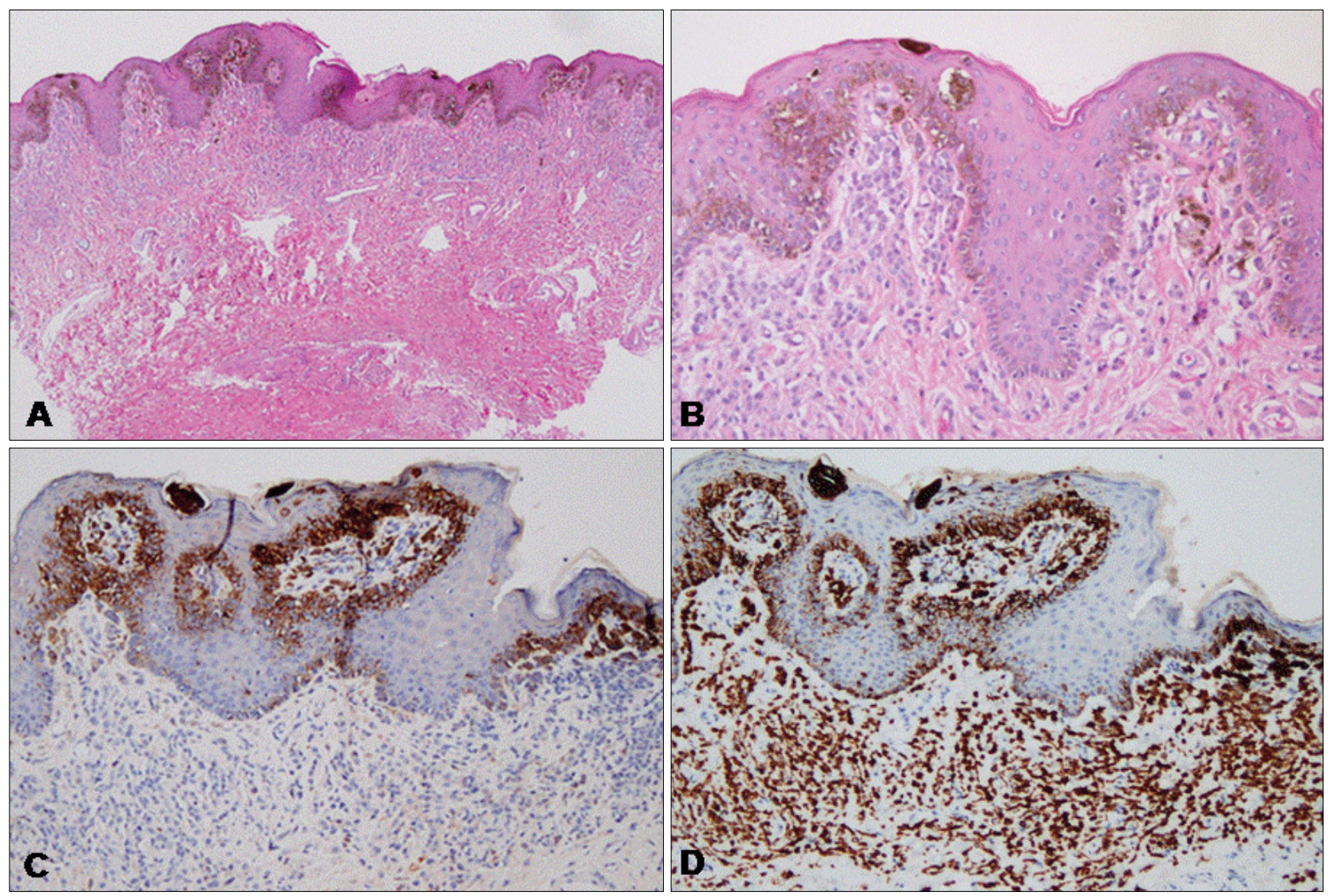

Fig. 2. Histopathological examination of the brown-black pigmented patches on the glans penis (A, B). Nests of nevus cells are present at the dermal-epidermal junction and upper dermis $(\mathrm{H} \& \mathrm{E}, \mathrm{A}: \times 40, \mathrm{~B}: \times 200)$. Immunohistochemical staining for HMB45 $(\mathrm{C})$ and melan A (D). Nevus cells show partial and strong reactivity to HMB45 and melan A, respectively $(C, D$ : the glans penis, $\times 100)$. Histopathological findings and immunohistochemical staining of a specimen from the prepuce reveal similar features.

for melan A (Fig. 2). The black patches were diagnosed as compound melanocytic nevus. We recommended that he be treated with an $\mathrm{Nd}$ :YAG laser, but he refused further treatment.

\section{DISCUSSION}

In this report, we experienced a rare kissing nevus of the penis. Kissing nevi are two adjacent brownish to black pigmented lesions that split along with division of the body during embryogenesis. Kissing nevi of the eyelids were first described by Von Micheal in 1908, and the name was first used by Fuchs ${ }^{13}$ in 1919. Since then, at least 45 additional cases have been reported ${ }^{1-12,14-17}$. Other locations and types of kissing nevi have been reported less frequently than that of the eyelids: nevus spilus of the eyelids $^{15}$, a divided mast cell nevus ${ }^{16}$, epidermal nevi of the finger ${ }^{17}$, and divided nevi of the penis ${ }^{4-11}$.

The borders that would be united into one and the mirror-image symmetric features are related to its embryologic mechanism. The eyelids start to form at weeks 5 $\sim 6$ of gestation and fuse at weeks 8 to 9 of gestation, then divide again at week 24 of gestation ${ }^{14}$. A kissing nevus of the eyelids may originate between weeks $8 \sim 24$ of gestation. During the fused state, melanoblasts are present at the borderline between the upper and lower eyelids. Subsequently, cellular division continues, and one nevus becomes two lesions that were located on adjacent sites. Kissing nevi of the penis are extremely rare. The first case was reported by Desruelles et al. ${ }^{4}$ in 1998, and only 12 cases of kissing nevi of the penis have been described $^{4-11}$ (Table 1). The same mechanisms can be applied to these lesions. Two invaginations appear in the digital edge of the penis from gestational week $11 \sim 14$. The epithelial glandular placode forms the glandular urethra and the epithelial preputial placode divides and forms the glans and the prepuce ${ }^{4}$. Desruelles et al. ${ }^{4}$ hypothesized that melanoblasts and melanocytes migrate to the lesion before separation of the glans from the prepuce at 12 weeks. He thought that after separation each nevus may develop independently. In contrast, Kono et al. ${ }^{6}$ suggested that melanoblasts start to migrate just after completion of 
Table 1. Kissing nevus of the penis

\begin{tabular}{rrcclc}
\hline No. & Age & Onset age & $\begin{array}{c}\text { Malignant } \\
\text { (or age when it was noticed) }\end{array}$ & Treatment \& results & Reference no. \\
\hline 1 & 7 & 3 & Absent & Not mentioned & 4 \\
2 & 18 & Not exactly described & Absent & Not mentioned & 5 \\
3 & 9 & Not exactly described & Absent & Not mentioned & 6 \\
4 & 21 & Not exactly described & Absent & Not mentioned & 6 \\
5 & 12 & 1 & Absent & Not mentioned & 6 \\
6 & 14 & 13 & Absent & Total excision: good result & 7 \\
7 & 30 & 30 & Present & Total excision and skin graft: good result & 8 \\
8 & 6 & 6 & Absent & Laser treatment: good result & 9 \\
9 & 11 & 8 & Absent & Total excision and skin graft: good result & 10 \\
10 & 20 & Not exactly described & Absent & Close observation & 11 \\
11 & 25 & Teens & Absent & Close observation & 11 \\
12 & 21 & 7 & Absent & Close observation & 11 \\
13 & 27 & 17 & Absent & Close observation & Our case \\
\hline
\end{tabular}

the invagination of the preputial epithelial placode.

Usually, almost all kissing nevi lesions of the penis are benign melanocytic nevi, except one case reported by Egberts et al. ${ }^{8}$ in 2007. Although that patient had no family history and was just 30-years-old when melanoma was detected, his lesions grew rapidly and atypical pigmentation was an unusual clinical feature.

Malignant melanoma of the penis is rare, accounting for $<2 \%$ of primary penile malignancies. Most cases of malignant melanoma of the penis occur in patients in their sixth and seventh decades ${ }^{18}$. So, when choosing a therapeutic option for a kissing nevus of the penis, the focus should be on esthetic and functional outcome. Surgical excision and reconstruction by skin grafting using remnant foreskin have been recently performed and showed favorable outcomes ${ }^{10}$. However, in cases in which nevi are large, as these lesions, surgical excision may cause a scar and deformity of the glans penis. Mandal et al. $^{19}$ treated congenital nevocellular nevi with a laser and showed satisfactory esthetic results. In our patient, we concluded that laser treatment was the best method to treat his lesion without complications. But, he denied any further treatment and chose observation.

We report here a rare case of kissing nevus of the penis that showed an obvious mirror-image symmetry relative to the coronal sulcus.

\section{REFERENCES}

1. Fuchs A. Divided nevi of the eyelids. Urol Cutaneous Rev 1950;54:88-90.

2. Harrison R, Okun M. Divided nevus. A clue to the intrauterine development of melanocytic nevi. Arch Dermatol 1960;82:235236.

3. Hamming N. Anatomy and embryology of the eyelids: a review with special reference to the development of divided nevi.
Pediatr Dermatol 1983; 1:51-58.

4. Desruelles F, Lacour JP, Mantoux F, Ortonne JP. Divided nevus of the penis: an unusual location. Arch Dermatol 1998;134: 879-880.

5. Choi GS, Won DH, Lee SJ, Lee JH, Kim YG. Divided naevus on the penis. Br J Dermatol 2000;143:1126-1127.

6. Kono T, Nozaki M, Kikuchi Y, Erçöçen AR, Hayashi N, Chan $\mathrm{HH}$, et al. Divided naevus of the penis: a hypothesis on the embryological mechanism of its development. Acta Derm Venereol 2003;83:155-156.

7. Phan PT, Francis N, Madden N, Bunker CB. Kissing naevus of the penis. Clin Exp Dermatol 2004;29:471-472.

8. Egberts F, Egberts JH, Schwarz T, Hauschild A. Kissing melanoma or kissing nevus of the penis? Urology 2007;69:384.e5-7.

9. Palmer B, Hemphill M, Wootton C, Foshee JB, Frimberger D. Kissing nevus discovered at circumcision consult. J Pediatr Urol 2010;6:318-319.

10. Higashida Y, Nagano T, Oka M, Nishigori C. Divided naevus of the penis. Acta Derm Venereol 2010;90:319.

11. Zhou C, Xu H, Zang D, Du J, Zhang J. Divided nevus of the penis. Eur J Dermatol 2010;20:527-528.

12. Sagong C, Ahn YS, Yu HJ, Kim JS. Congenital divided nevus of the eyelid. Korean J Dermatol 2007;45:864-866.

13. Fuchs A. Ueber geteilte naevi der augenlider. Klin Monatsbl Augenheikd 1919;63:678-683.

14. Guerra-Tapia A, Isarría MJ. Periocular vitiligo with onset around a congenital divided nevus of the eyelid. Pediatr Dermatol 2005;22:427-429.

15. Sato $\mathrm{S}$, Kato $\mathrm{H}$, Hidano A. Divided nevus spilus and divided form of spotted grouped pigmented nevus. J Cutan Pathol 1979; 6:507-512.

16. Niizawa $M$, Masahashi $T$, Maie $O$, Takahashi S. A case of solitary mastocytoma suggesting a divided form of mast cell nevus. J Dermatol 1989;16:402-404.

17. Hayashi N, Soma Y. A case of epidermal nevi showing a divided form on the fingers. J Am Acad Dermatol 1993;29:281-282.

18. Demitsu T, Nagato $H$, Nishimaki K, Okada O, Kubota T, Yoneda $\mathrm{K}$, et al. Melanoma in situ of the penis. J Am Acad Dermatol 2000;42:386-388.

19. Mandal A, Al-Nakib K, Quaba AA. Treatment of small congenital nevocellular naevi using a combination of ultrapulse carbon dioxide laser and Q-switched frequency- doubled Nd-YAG laser. Aesthetic Plast Surg 2006;30:606-610. 